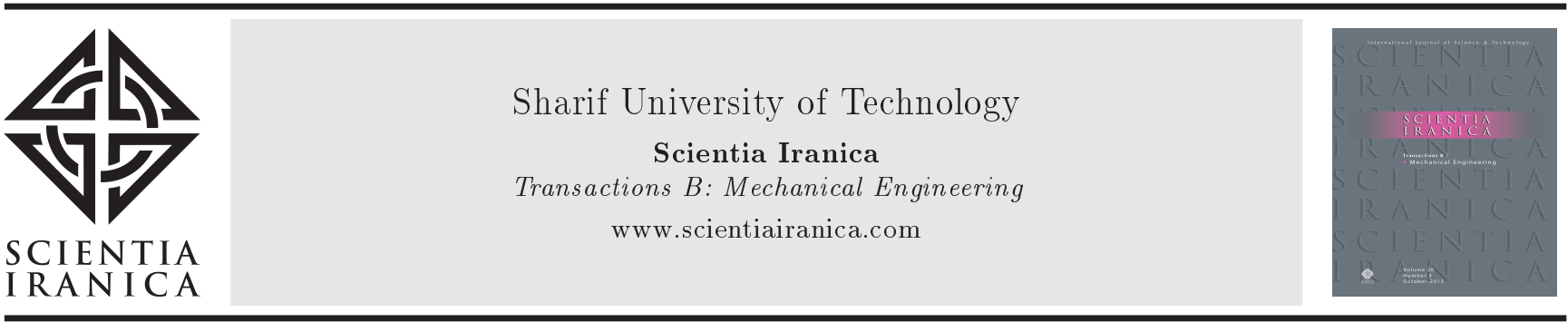

\title{
Light oil-gas two-phase flow pattern identification in different pipe orientations: An experimental approach
}

\author{
P. Hanafizadeh*, J. Eshraghi, Y. Nazari, K. Yousefpour and \\ M.A. Akhavan Behabadi \\ School of Mechanical Engineering, College of Engineering, University of Tehran, Tehran, P.O. Box: 11155-4563, Iran.
}

Received 22 February 2016; received in revised form 23 May 2016; accepted 13 August 2016

\author{
KEYWORDS \\ Experimental \\ two-phase flow \\ investigation; \\ High-speed \\ photography; \\ Oil-air two-phase flow \\ patterns; \\ Flow maps in inclined \\ pipe.
}

\begin{abstract}
In this paper, an experimental study on the flow patterns of two-phase air-light oil flow is performed in a $20 \mathrm{~mm}$ diameter pipe with a length of $6 \mathrm{~m}$ in different orientations with pipe angles in the range of -45 to +45 . The flow regimes are captured by a high-speed camera. In the experiments, the following are used: the air with the viscosity of $0.019 \mathrm{mPa} . \mathrm{s}$ and the density of $1.2 \mathrm{~kg} / \mathrm{m}^{3}$ as well as the light oil with the viscosity of $2.6 \mathrm{mPa} . \mathrm{s}$ and the density of $840 \mathrm{~kg} / \mathrm{m}^{3}$. During the experiments, different flow patterns are observed such as bubbly, slug, smooth stratified, wavy stratified, and annular flows. Flow regimes in different pipe inclination angles are inspected in a two-phase air-light oil flow, and flow pattern maps are proposed for every pipe inclination angle. In addition, a comprehensive study on the major forces acting on dispersed phase is presented theoretically to perform a thorough discussion on the effects of pipe inclination angle on transition boundaries between flow patterns in the two-phase air-light oil flow. It is inferred that non-stratified flows are dominant flow patterns in the upward flows, and stratified flows are dominant flow patterns in the downward flows.
\end{abstract}

(C) 2017 Sharif University of Technology. All rights reserved.

\section{Introduction}

The gas-liquid two-phase flows have been largely used in various industries such as refrigeration industry. For each of these applications, having the reliable data about the gas-liquid two-phase flow patterns in different conditions is necessary due to strong effects of the flow patterns on important parameters such as friction and heat transfer coefficients. During the past decades, gas-liquid two-phase flow patterns have attracted the attention of researchers, but most of them employed water as the liquid phase in their

\footnotetext{
* Corresponding author. Tel.: +982188353894; Fax: +982188013029

E-mail address: hanafizadeh@ut.ac.ir (P. Hanafizadeh)
}

doi: $10.24200 /$ sci. 2017.4303 experiments. Research about gas-oil two-phase flows is rarely conducted and also in this limited research, most of the researchers focused on the gas-heavy oil flows in horizontal pipes. Furthermore, research about gas-light oil two-phase flows as well as research in the field of gas-oil two-phase flows in inclined pipes have been rarely done.

In oil pipelines from oil wells to oil refinery plants, due to the presence of gas in oil wells, the gas-oil twophase flow is common. The oil refinery plants are often far from the oil wells, and angulation of pipelines is inevitable due to unevenness of the ground in this distance.

One of the first studies on gas-liquid two-phase flow patterns in horizontal pipes was done by Mandhane et al. [1]. They presented a plan for flow patterns of water and air in horizontal pipes with a small diameter. Weisman et al. [2] investigated the effect 
of pipes diameter and the fluid properties on the gasliquid flow patterns in horizontal pipes. Lin and Hanratty [3] proposed flow maps for horizontal tubes with the diameters of 2.54 and $9.53 \mathrm{~cm}$. Jepson and Taylor [4] conducted a research to study the transition of slug flow pattern to other flow patterns in horizontal pipes with a large diameter.

Recently, the study of gas-oil flow patterns in horizontal tubes has been of interest to researchers. Lu et al. [5] investigated an experimental and numerical study on the nitrogen-oil flow in the horizontal tube with the diameter of $125 \mathrm{~mm}$. They focused on the transition of flow patterns from stratified flow to slug flow. Jamari et al. [6] studied the transition of flow patterns from slug to annular flows inside a horizontal tube with $78 \mathrm{~mm}$ diameter for two different two-phase flows of water-air and oil-air. Foletti and et al. [7] carried out a research to study the flow pattern of airheavy oil two-phase flow in a horizontal tube with the diameter of $22 \mathrm{~mm}$. They also proposed a flow pattern map for this investigation, and then compared this map to the theoretical and practical values achieved by Baker [8], Mandhane et al. [1], and Petalas and Aziz [9]. The results had small conformity, and they concluded that the liquid properties have strong effects on the flow pattern map. Matsubara and Naito [10] studied the effect of liquid viscosity on the flow patterns of airliquid two-phase flow in a horizontal tube with $20 \mathrm{~mm}$ diameter and used different liquids with the viscosity of 1-11000 mPa.s. Zhao et al. [11] investigated the effect of viscosity changes of oil phase on the characteristics of the gas-viscose oil two-phase flow in a horizontal tube of $26 \mathrm{~mm}$ diameter. They also presented that the characteristics of viscous flow of the gas-oil twophase flow are significantly different from low-viscosity kind of the two-phase flow. They studied the viscosity in the range of $1000-75000 \mathrm{cp}$. Monni and et al. [12] conducted a research to characterize the flow patterns in the horizontal tube with $19.5 \mathrm{~mm}$ diameter for water-air two-phase flow. They also used the wiremesh sensor to determine the direction of flow patterns. Khaledi et al. [13] studied the flow patterns of twophase gas-viscosity oil in the tube with the diameter of $69 \mathrm{~mm}$. They employed the oil with viscosity of 32$100 \mathrm{cp}$ and sulfur hexafluoride gas as liquid and gas phases, respectively. They focused on the heavy oil with high viscosity, and the least viscous oil used in their experiment was almost equivalent to 10 times the viscosity of oil used in the present work.

The study on gas-liquid two-phase flow patterns in inclined tubes has also attracted the attention of researchers. Barnea et al. [14] investigated the transition of gas-liquid flow patterns in horizontal and inclined tubes. They studied the water and air flow patterns in tubes with 1.95 and $2.55 \mathrm{~cm}$ diameters in the inclination angle range of -10 to +10 degrees and compared the obtained results with those of the presented model by Taitel and Dukler [15]. Barnea et al. [16] conducted a research to study the transition of flow patterns in downward flow for the water-air two-phase flow from the horizontal to vertical positions. This measurement was done in the tubes with diameters of 2.55 and $5.1 \mathrm{~cm}$. They stated that the angle change in the downward flow has the most effect on the transitions of stratified flow. Kokal and Stanislav [17] investigated the flow patterns of oil-air two-phase in horizontal pipe and slightly inclined pipes, and they used the quite light oil, $7 \mathrm{mPa} . \mathrm{s}$ viscosity, and $858 \mathrm{~kg} / \mathrm{m}^{3}$ density. They also investigated the flow patterns for inclination from -9 to +9 degrees in the pipes with the diameters of $25.8,51.2$, and $76.3 \mathrm{~mm}$. They stated that flow pattern model of Taitel and Dukler [15] was not able to predict all flow patterns. Finally, they proposed an advanced model for prediction of all flow patterns, and declared that flow patterns were extremely dependent on inclination of the tube. Wongwises and Pipathattakul [18] studied the water-air two-phase flow patterns in a tube with the inner diameter of $8 \mathrm{~mm}$ in three different pipe inclination angles of $0,+30$, and +60 degrees. Ghajar and Bhagwat [19] conducted a research to study the two-phase flow phenomenon in the pipe with the diameter of $12.7 \mathrm{~mm}$, and they studied the flow patterns with different inclination angles of -20 to +20 degrees. According to the literature and studies on gasliquid two-phase flow patterns, it is concluded that no research has been done on gas-light oil flow patterns in the pipes with small diameter and in wide range of pipe inclination angles. To sum up, the presented studies in the literature show the importance of implementing this research; we show the most relevant and recent studies in the area of two-phase flow patterns in Table 1.

In the present experimental study, flow patterns of air and light oil two-phase flow are investigated in the transparent pipe with the diameter of $20 \mathrm{~mm}$ and the length of $6 \mathrm{~m}$ in different inclination angles of $\pm 5, \pm 10, \pm 15, \pm 30$, and \pm 45 . The flow patterns in different inlet conditions are visualized by the aid of a high-speed digital camera to detect the two-phase flow regimes. In addition, a comprehensive force analysis of dispersed phase of the two-phase flow is carried out to enable us to present the effects of pipe inclination on transition boundaries of flow maps. First, different flow patterns in this study are introduced and a flow map for horizontal pipe is presented. Next, the flow maps for different inclination angles are introduced and differences in flow maps of upward and downward flows are investigated. Specific and wide ranges of inclination angles and lack of information on the flow patterns of liquid phase in the present study (light oil with viscosity of $2.6 \mathrm{mPa} . \mathrm{s})$ are the important features of this work. 
Table 1. Investigations of experimental two-phase flow patterns.

\begin{tabular}{|c|c|c|c|c|}
\hline Author(s) & Fluids & $\begin{array}{c}\text { Inclination } \\
\text { angle } \\
\text { (degree) }\end{array}$ & $\begin{array}{c}\text { Pipe } \\
\text { diameter } \\
(\mathrm{mm})\end{array}$ & $\begin{array}{c}\text { Test pipe } \\
\text { length } \\
(\mathrm{m})\end{array}$ \\
\hline Khaledi et al. [13] & $\mathrm{SF}_{6} /$ oil & Horizontal & 69 & 51.8 \\
\hline Wongwises \& Pipathattakul [18] & Air/water & 0 to $60^{\circ}$ & 8 & 0.88 \\
\hline Ghajar \& Bhagwat [19] & Air/water & $-20^{\circ}$ to $+20^{\circ}$ & 12.7 & Not reported \\
\hline Hanafizadeh et al. [20] & Air/water & Vertical & 50 & 6 \\
\hline Hanafizadeh et al. [21] & Oil/water & $-45^{\circ}$ to $+45^{\circ}$ & 20 & 6 \\
\hline Ghanbarzadeh et al. [22] & Air/water & Vertical & 50 & 6 \\
\hline Ghajar and Tang [23] & Air/water & $-2^{\circ}$ to $+7^{\circ}$ & 27.9 & 2.79 \\
\hline Xia and Chai [24] & $\begin{array}{l}\text { Air/water \& Air/SDS } \\
\text { surfactant solution }\end{array}$ & 0 to $15^{\circ}$ & 59 & 11 \\
\hline Smith et al. [25] & $\mathrm{SF}_{6} / \mathrm{oil}$ & Horizontal & 69 & 52 \\
\hline Hanafizadeh et al. [26] & Oil/water & $-45^{\circ}$ to $+45^{\circ}$ & 20 & 6 \\
\hline Xi-mao et al. [27] & Heavy oil/water/gas & Vertical & 50 & 18.5 \\
\hline Zhao et al. [28] & Gas/highly viscous liquid & Horizontal & 74 & 17 \\
\hline Losi et al. [29] & Air/high viscosity oil & Horizontal & 22 & 9 \\
\hline Losi and Poesio [30] & Air/paraffin oil & 0 to $5^{\circ}$ & 22 & 9 \\
\hline Al-Safran et al. [31] & Air/viscous mineral oil & Horizontal & 50.8 & 18.9 \\
\hline
\end{tabular}

\section{Experimental apparatus}

The experimental apparatus is shown schematically in Figure 1. The air and oil flows are injected by the air compressor and displacement pumps into the test pipe, respectively. The fed air flow by the compressor is passed through the filter to remove the moisture, and a pressure regulator valve adjusts its pressure. In order to measure the air flow rate, three flow meters with the ability of measuring different ranges are used. An oil flow meter device is also used to determine the oil flow rate.

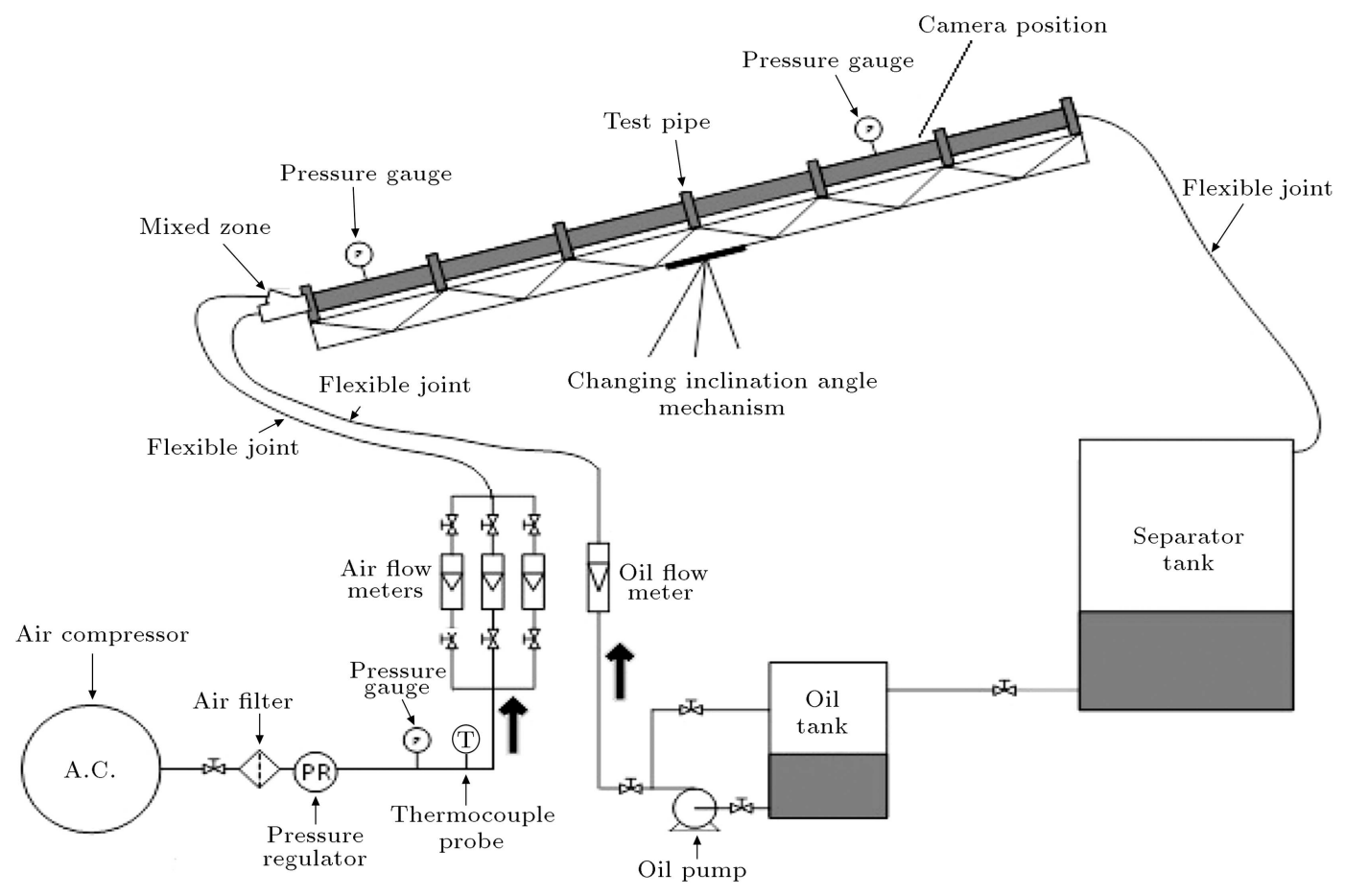

Figure 1. Schematic of experimental setup. 
Table 2. Air and light oil superficial velocities.

\begin{tabular}{|c|c|c|c|c|c|c|c|c|c|c|}
\hline & \multicolumn{9}{|c|}{ Air superficial velocity $(\mathrm{m} / \mathrm{s})$} & \\
\hline & 0.076 & 0.152 & 0.385 & 0.48 & 0.61 & 0.77 & 1.54 & 2.3 & 3.08 & \\
\hline & 3.85 & 5.39 & 5.95 & 6.56 & 7.14 & 7.77 & 8.34 & 10.72 & 14.88 & \\
\hline \multicolumn{11}{|c|}{ Oil superficial velocity $(\mathrm{m} / \mathrm{s})$} \\
\hline 0.058 & 0.117 & 0.292 & 0.584 & 0.876 & 1.16 & 1.46 & 1.75 & 2.04 & 2.33 & 2.63 \\
\hline
\end{tabular}

Table 3. Operational conditions of experiments and fluids properties.

\begin{tabular}{|c|c|c|}
\hline Parameter & \multicolumn{2}{|r|}{ Value } \\
\hline Pressure (bar) & $1-3$ & \\
\hline Temperature $\left({ }^{\circ} \mathrm{C}\right)$ & 20 & \\
\hline Inclination angle (degree) & $0, \pm 5, \pm 10$ & $\pm 15, \pm 30$, and \pm 45 \\
\hline Superficial air velocity $(\mathrm{m} / \mathrm{s})$ & $0.076-14.88$ & \\
\hline Superficial oil velocity $(\mathrm{m} / \mathrm{s})$ & $0.058-2.63$ & \\
\hline Fluids' properties Densit & $\left(\mathrm{kg} / \mathrm{m}^{3}\right)$ & Viscosity (mPa.s) \\
\hline Oil & 340 & 2.6 \\
\hline Air & 204 & 0.018 \\
\hline
\end{tabular}

For visual observation of the two-phase flow patterns, the pipe is made of a transparent acrylic glass. The test pipe with the inner diameter of $20 \mathrm{~mm}$ and the length of $6 \mathrm{~m}$ includes 6 parts with the length of $1 \mathrm{~m}$ connected together in equal diameters and located in the space frame. The space frame was installed on a seesaw to change the angle of the test pipe in the ranges of -45 to +45 . The angles measurement in each experiment is performed by a digital leveling system. A fixer is also employed on the seesaw to prevent the deviations of set angles caused by flow vibrations in each step of the experiment. In addition, at the beginning of the test pipe path, a T-junction is used to mix the two phases.

The flow regimes are observed and recorded by a high-speed CCD camera with 1200 frames per second. Images are captured at the last one-meter part of the pipe with various frame rates of $60,300,600$, and $1200 \mathrm{fps}$ depending on superficial velocities of the air and oil by using appropriate illumination.

The ranges of the compressed air pressure are variable from the atmosphere pressure to 3 bar based upon the test conditions. The two-phase flow of air and oil, after passing the test pipe, is poured into the separator tank. After the oil-air separation, the air is discharged into the atmosphere and the oil is transferred from separator to an oil storage tank. Avoiding the use of separator tank in the test loop results in permanently foamy oil flow.

In the experiments, the light oil with the viscosity of $2.6 \mathrm{mPa}$.s and density of $840 \mathrm{~kg} / \mathrm{m}^{3}$ is applied as the liquid phase at $20^{\circ} \mathrm{C}$. To obtain a reliable flow map, it is necessary to cover all the flow regimes in different pipe orientations. To do so, the superficial velocity is changed from 0.058 to $2.63 \mathrm{~m} / \mathrm{s}$ for oil and from 0.076 to $14.88 \mathrm{~m} / \mathrm{s}$ for air.

The main purpose of the present study is to determine flow regimes in various superficial velocities of two-phase air-light oil flow in different pipe inclination angles. Air and light oil superficial velocities are mentioned in Table 2. More than 2100 experiments are implemented to obtain flow regimes of all the considered inlet conditions (for each inclination angle, 198 flow patterns are determined with different twophase flow inlet conditions).

Based on the variation of air and oil superficial velocities mentioned in Table 2, the experiments are implemented in a way that in each inclination angle, the superficial velocity of oil is kept at $0.058 \mathrm{~m} / \mathrm{s}$ and superficial velocity of air is varied from 0.076 to $14.88 \mathrm{~m} / \mathrm{s}$. Then, the superficial velocity of oil is increased to $0.117 \mathrm{~m} / \mathrm{s}$ and superficial velocity of air is swept from 0.076 to $14.88 \mathrm{~m} / \mathrm{s}$ again, and the same procedure is conducted until all sequences are tested. To sum up, operational conditions and fluid properties are presented in Table 3 .

To realize the results reliability, the parameters' measurement uncertainty in the experiments is shown in Table 4.

\section{Force analysis}

In this section, the forces acting on the dispersed phase are investigated in a two-phase flow. Generally, three 
Table 4. Uncertainty in the measurement.

\begin{tabular}{ll}
\hline \multicolumn{1}{c}{ Parameter } & Uncertainty \\
\hline Pipe diameter & $\pm 0.01 \mathrm{~mm}$ \\
Angles & $0.003 \%$ \\
Pressure & $0.03 \%$ \\
Temperature & $0.1^{\circ} \mathrm{C}$ \\
Gas flow meter & $1.5 \%$ \\
Oil flow meter & $0.5 \%$ \\
\hline
\end{tabular}

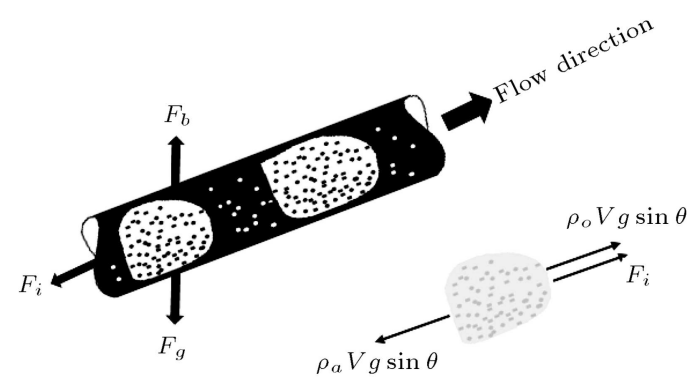

(a)

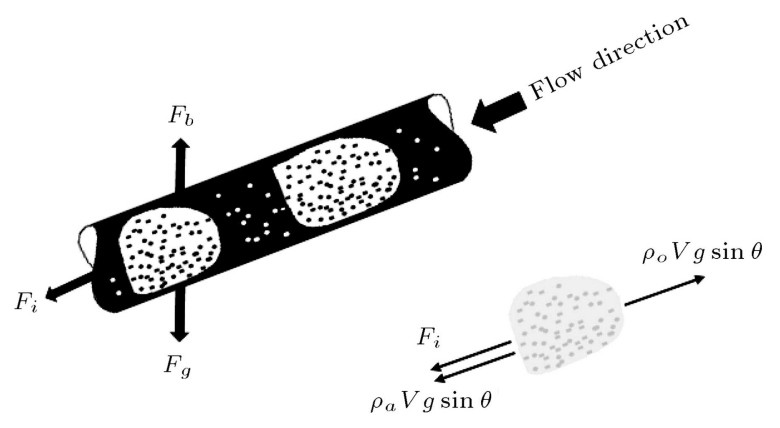

(b)

Figure 2. Air bubble force free diagram in (a) upward flow and (b) downward flow.

dominant forces influence the dispersed phase in airoil flow: buoyancy force, gravity force, and inertia force. It should be mentioned that there are some other forces due to velocity and viscosity differences between the phases that affect the dispersed phase. However, these forces can be ignored in this study due to the least effects in comparison with buoyancy, gravity, and inertia forces. It is obvious that the dispersed phase is always accelerated by the inertia force, whether flow is upward or downward. On the other hand, behaviors of buoyancy and gravity forces are different in upward and downward flows. Free body diagrams of an air bubble in oil in upward and downward flows are shown in Figure 2(a) and (b), respectively. The fluids temperature is assumed constant through the test loop.

$F_{b}, F_{g}$, and $F_{i}$ in Figure 2 represent buoyancy force, gravity force, and inertia force, respectively. Also, $\theta$ is the pipe inclination angle, $V$ is the air bubble volume, and $\rho_{o}$ and $\rho_{a}$ are oil and air densities, respectively.
For a bubble of air in upward flow, Eq. (1) is obtained from the second Newton's law:

$$
F_{i}+\left(\rho_{o}-\rho_{a}\right) V g \sin \theta=m_{b} a
$$

where $m_{b}$ is the mass air bubble and $a$ is the bubble acceleration. It is obvious that the term of $\left(\rho_{o}-\right.$ $\rho_{a}$ ) has a positive value, and subsequently the air bubble is accelerated and its velocity is increased as the inclination angle increases.

For an air bubble in a downward flow, Eq. (2) is obtained from the second Newton's law:

$$
F_{i}+\left(\rho_{a}-\rho_{o}\right) V g \sin \theta=m_{b} a .
$$

It is clear that the term $\left(\rho_{a}-\rho_{o}\right)$ has a negative value; as a result, the bubble is decelerated and the bubble velocity decreases by decreasing inclination angles.

Considering the above explanations, buoyancy force accelerates air bubble and gravity force decelerates air bubble in upward flow. On the other hand, in downward flow, gravity force accelerates bubble and buoyancy force decelerates bubble. As the oil density is greater than the air density, the dispersed phase (i.e., air phase) velocity increases in upward flow and decreases in downward flow. The difference between gravity and buoyancy forces becomes greater as the pipe inclination angle increases. Consequently, the buoyancy force becomes more dominant in high inclined upward flow and gravity force becomes more dominant in high inclined downward flow, respectively.

\section{Results and discussion}

In this section, results of experimental investigation into air-light oil two-phase flow are presented. To present the extracted flow pattern maps in different orientations, superficial velocities of phases are used instead of physical velocities for comparability of experimental results with other researchers' data. Eq. (3) is used to obtain the superficial velocity of continuous and dispersed phases:

$$
u_{s i}=u_{i} \times \alpha_{i}
$$

where $u_{s i}$ is phase $i$ superficial velocity, $u_{i}$ is phase $i$ velocity, and $\alpha_{i}$ is phase $i$ void fraction. Phase $i$ void fraction is also obtained from Eq. (4):

$$
\alpha_{i}=\frac{A_{i}}{A_{\mathrm{tot}}}
$$

where $A_{i}$ and $A_{\text {tot }}$ are cross-section area of phase $i$ and total cross-section area of the pipe, respectively. In this study, the void fraction of each phase is estimated by the ratio of each phase volumetric flux to the total flux.

In each pipe inclination angle, 198 flow patterns are obtained at the mentioned ranges of superficial 
velocities to extract the flow pattern maps. In the rest of this section, investigation results of air-light oil twophase flow patterns in different pipe orientations are presented and compared so as to identify the effects of pipe inclination angles on flow patterns.

\subsection{Horizontal flow}

In this experimental study, six distinguishable flow patterns are observed in horizontal orientation of the pipe: annular, churn, wavy stratified, stratified, slug, and bubbly flows. The captured images of the study in the horizontal flow are depicted in Figure 3. Considering the obtained raw experimental data, in horizontal flow, bubbly flow is identified at low air superficial velocities and high oil superficial velocities. At high oil superficial velocities with an increase in the air superficial velocity, bubbly flow is replaced by slug flow. In addition, at low oil and air superficial velocities, stratified flow is obtained in the pipe horizontal orientation and with increase in air superficial velocity, stratified flow is switched to wavy stratified and annular flows at intermediate and high air superficial velocities, respectively.

It should be mentioned that although a particular flow regime is observed in a wide range of air and oil superficial velocities, there are some differences on size or distribution of dispersed phase in different conditions. For example, the air plug size is a strong function of oil superficial velocity (see Figure 4).

The air-light oil two-phase flow pattern map in the horizontal orientation of the pipe is extracted from the
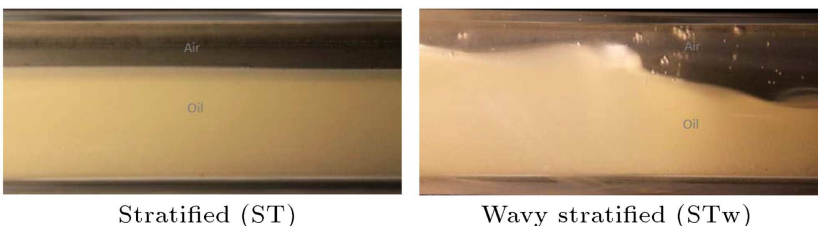
Wavy stratified (STw)
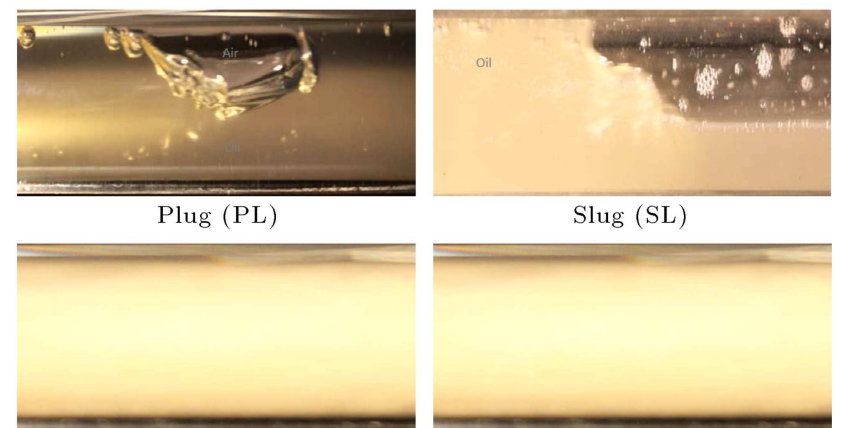

Slug (SL)

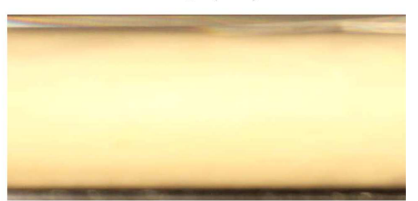

Annular (AN)

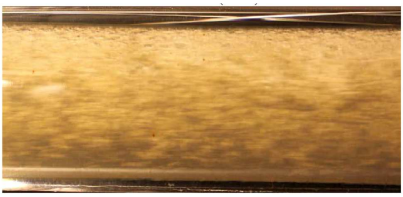

Dispersed bubble (DB)

Figure 3. Photographcial images of distinguishable horizontal flow patterns.

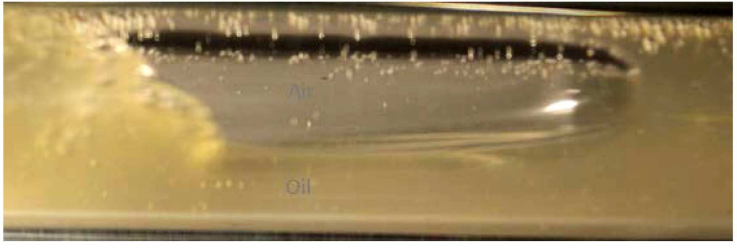

(a)

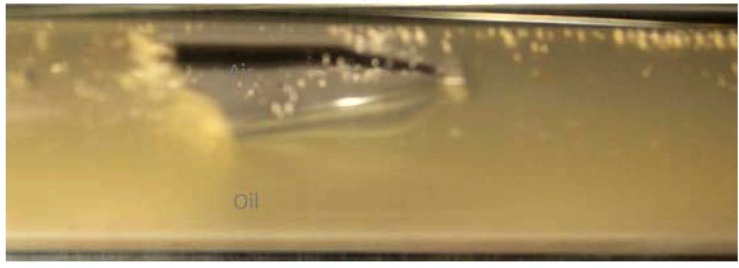

(b)

Figure 4. Dependence of plug size in plug flow on oil and air superficial velocities: (a) Plug flow at $U_{s a}=0.152 \mathrm{~m} / \mathrm{s}$ and $U_{s o}=0.117 \mathrm{~m} / \mathrm{s}$ and (b) plug flow at $U_{s a}=0.152 \mathrm{~m} / \mathrm{s}$ and $U_{\text {so }}=0.876 \mathrm{~m} / \mathrm{s}$.

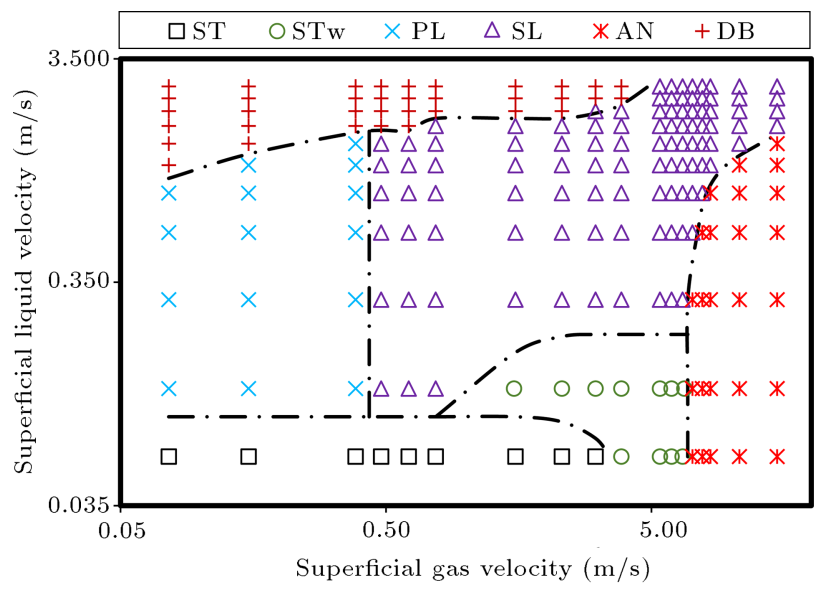

Figure 5. Horizontal flow-pattern map.

raw experimental data, shown in Figure 5. In this flow regime map, superficial velocities of oil and air $\left(U_{s o}\right.$ and $\left.U_{s a}\right)$ correspond to the $y$-axis and $x$-axis, respectively.

In addition, to show the validity of presented results, the proposed horizontal flow map is compared with flow pattern map of Taitel and Dukler [15] in Figure 6.

\subsection{Inclined upward flows}

In this section, flow pattern is investigated in the upward inclined pipe with different inclination angles. First, patterns of air-light oil two-phase flow are investigated for the pipe inclination angle of $+5^{\circ}$ and a flow pattern map is obtained from the raw experimental data. The extracted flow pattern map at this pipe inclination angle is depicted in Figure 7.

Figure 7 shows that by increasing the pipe inclination angle up to $+5^{\circ}$, the transition boundary between bubbly and slug flows shifts to the right-hand side of the flow map, and transition boundary between 


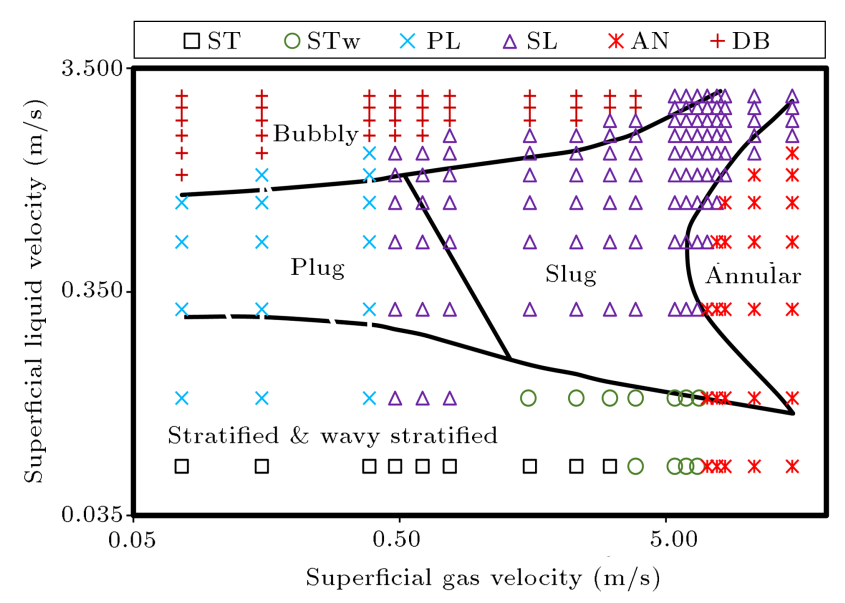

Figure 6. Comparison of the proposed horizontal flow-pattern map in this study with one of the most cited flow map by Taitel and Dukler [15].

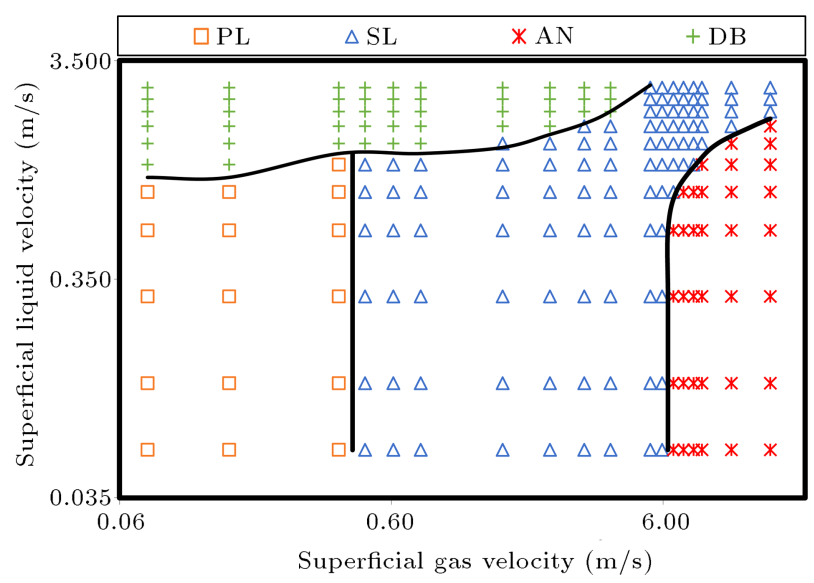

Figure 7. Experimental flow pattern map of air-light oil two-phase flow in pipe with the inclination angle of $+5^{\circ}$.

slug and annular flows shifts to the left-hand side a bit. It means that the transition between slug and annular flow regimes occurs in lower light oil superficial velocities. At this pipe inclination angle, plug and slug flows have been replaced by the bubbly flow in a few points, and slug flow has been replaced by annular flow in few points as well. These small changes in the transition boundary between annular, slug, and bubbly flows are due to buoyancy force which acts toward flow direction and causes the flow to be faster. This analysis compatible with analytical investigation was explained in Section 3.

Next, air-light oil two-phase flow patterns are investigated in inclination angle of $+15^{\circ}$. Figure 8 shows the flow pattern map in this inclination angle. It is found out that by increasing the pipe inclination angle up to $+15^{\circ}$, the transition boundaries between slug and bubbly flows and between slug and plug flows have been shifted to the right-hand side of the flow map more than flow map at the inclination angle of

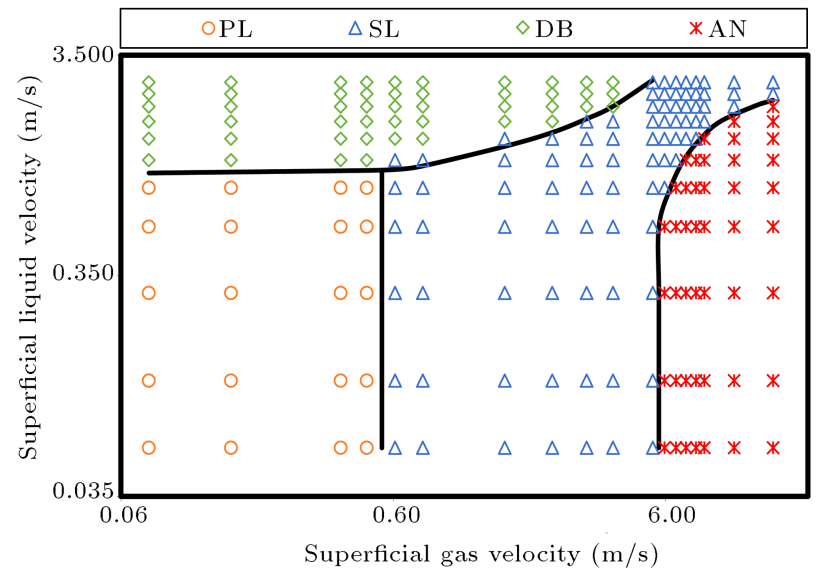

Figure 8. Experimental flow pattern map of air-light oil two-phase flow in pipe with the inclination angle of $+15^{\circ}$.

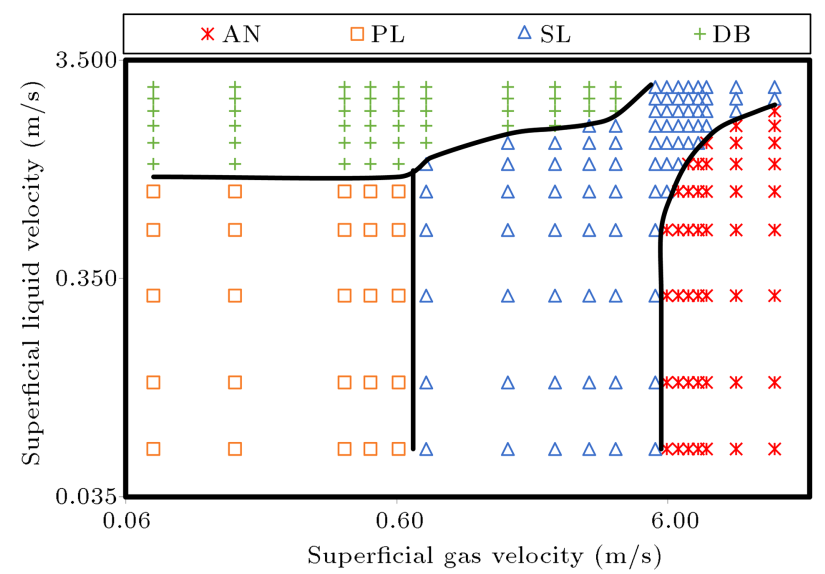

Figure 9. Experimental flow pattern map of air-light oil two-phase flow in pipe with the inclination angle of $+30^{\circ}$.

$+5^{\circ}$, and some other points that experienced slug flow in $+5^{\circ}$ inclination have been replaced by bubbly flow and the same has occurred for slug and annular flows. Also, the slug and annular flows of transition boundary have been drifted to the left-hand side of the flow map. It seems that transition boundaries in upward flow are shifted in the horizontal direction and are not shifted in the vertical direction.

Figure 9 shows the air-light oil two-phase flow pattern map in the inclined pipe of $+30^{\circ}$. It is clear that by increasing the pipe inclination angle, the transition boundary between slug and bubbly flows moves further to the right-hand side of the flow pattern map; in this inclination angle, bubbly and slug flows have occupied most of the upper areas of the flow pattern map. The results also show that the number of annular flows has not changed significantly.

Figure 10 demonstrates the flow-pattern map of air-light oil two-phase upward flow in the inclined pipe of $+45^{\circ}$. In this pipe inclination, slug flows have occupied the least area of the flow pattern map in 


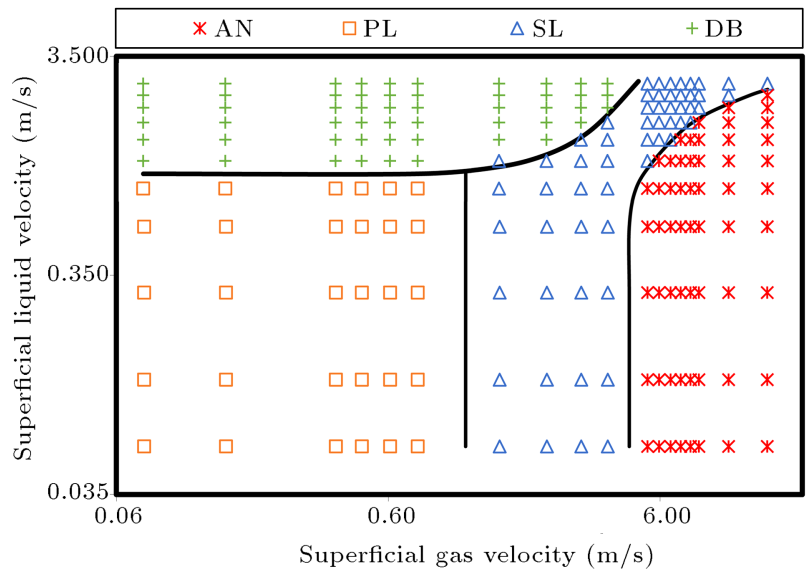

Figure 10. Experimental flow pattern map of air-light oil two-phase flow in pipe with the inclination angle of $+45^{\circ}$.

comparison with the flow maps in other inclination angles. Also, the transition boundary between plug and slug flows shifts further to the right-hand side of the map. In addition, transition boundary between annular and slug flows is drifted to the left of the flow pattern map, and annular flow regime has the most occupied area in the map between other inclination angles flow maps.

Considering the above explanations, for inclined upward flow, buoyancy force accelerates dispersed phase and gravity force decelerates dispersed phase flow. Since buoyancy force is greater than gravity force, the dispersed phase flow is accelerated. It should be mentioned that bubbly and plug flows become dominant flows and the transition boundaries between the mentioned flows and other flow patterns are shifted to the right-hand side of the flow pattern map. This mechanism is continued such that in highly inclined upward flows such as those of $+45^{\circ}$ angle, bubbly and plug flows occupy more than the half of the flow pattern map. In addition, in inclined upward flow, transition boundaries are moved only horizontally.

\subsection{Inclined downward flows}

In the following, air-light oil two-phase flow is investigated in the inclined downward pipe. First, flow in pipe with inclination angle of $-5^{\circ}$ is investigated. Figure 11 depicts the obtained flow regime map of air-light oil two-phase flow in this inclination angle.

Figure 11 reveals that with a decrease in the pipe inclination angle, slug and bubbly flows shift slightly to the right-hand side of the flow map, and stratified flow moves to the upward and right-hand side of the flow pattern map. In other words, transition boundaries between slug and bubbly flows and between annular and slug flows shift to the right-hand side, and the transition boundaries between stratified and nonstratified flows drift to the upper parts of the flowpattern map. The movement of transition boundary

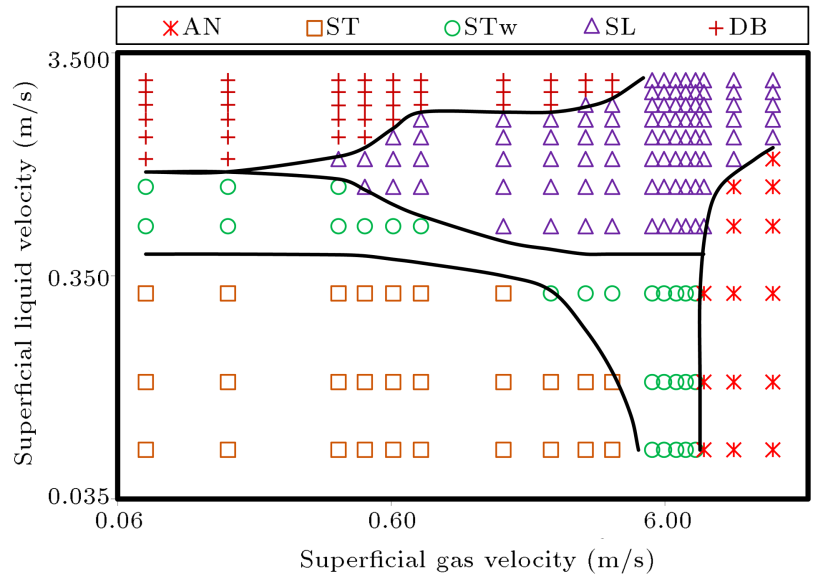

Figure 11. Experimental flow pattern map of air-light oil downward two-phase flow in pipe with the inclination angle of $-5^{\circ}$.

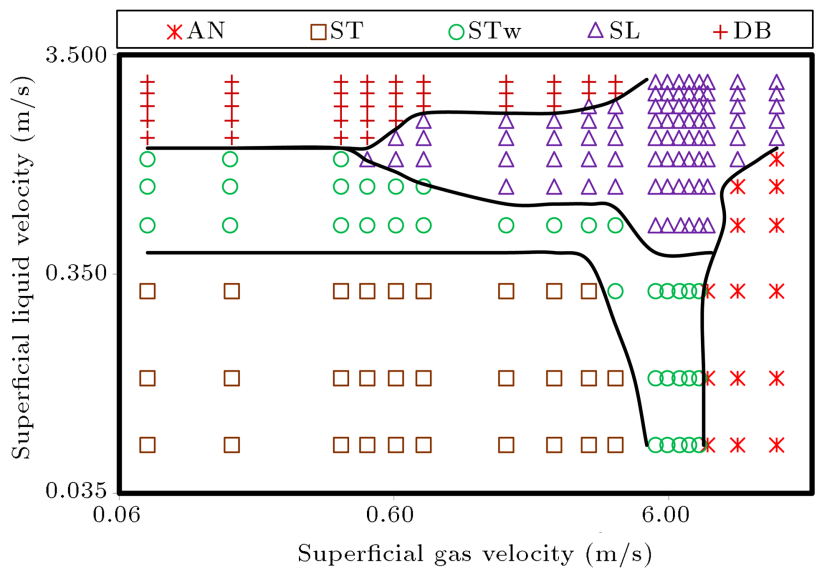

Figure 12. Experimental flow pattern map of air-light oil downward two-phase flow in pipe with the inclination angle of $-10^{\circ}$.

between the stratified and non-stratified flows is due to effects of buoyancy force, acting against flow direction and decelerating dispersed phase.

Flow regime map of air-light oil two-phase downward flow in the pipe with an inclination angle of $10^{\circ}$ is depicted in Figure 12.

It is concluded that decreasing the pipe inclination angle to $-10^{\circ}$ results in moving the transition boundary between stratified and non-stratified flows towards the upper parts of the flow map. It is predictable that the further decrease in the pipe inclination angle, the more occupied the flow map area by stratified flow.

The flow pattern map of air-light oil two-phase flow in the inclined pipe of $-15^{\circ}$ is shown in Figure 13. The mentioned figure discloses that the previous prediction is right, and with decreasing the pipe inclination angle toward high-inclined downward angles, effect of buoyancy force intensifies. Also, the number of annular, slug, and bubbly flows has decreased in 


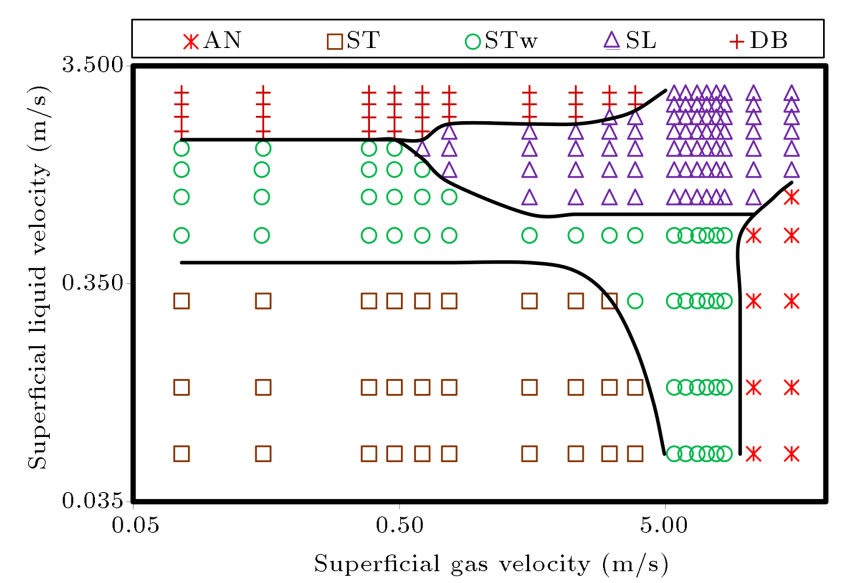

Figure 13. Experimental flow pattern map of air-light oil downward two-phase flow in pipe with the inclination angle of $-15^{\circ}$.

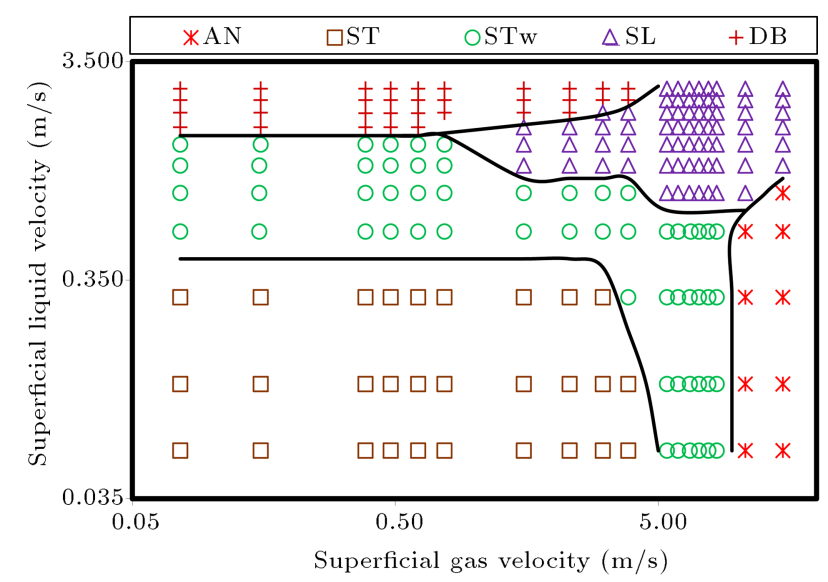

Figure 14. Experimental flow pattern map of air-light oil downward two-phase flow in pipe with the inclination angle of $-30^{\circ}$.

the inclination angle of $15^{\circ}$. In industry, the desirable flow pattern is the stratified flow for both flow damage reductions in instrumentation and oil transfer. Slug and bubbly flow patterns cause cavitation or impulse in the valves and other equipment.

Air-light oil two-phase flow patterns in the pipe with inclination angles of $30^{\circ}$ and $45^{\circ}$ in the downward flow are shown in Figures 14 and 15, respectively.

Figure 14 presents that slug flow shifts to the right-hand side of the flow map, and therefore the transition boundary of the slug and wavy stratified flows moves to the higher oil and air superficial velocities. In addition, as depicted in Figure 14, the number of stratified flows has remained constant, and the number of wavy stratified flows has increased in the inclination angle of $-30^{\circ}$.

By decreasing the inclination angle to $-45^{\circ}$, the number of tests with slug flow is further decreased. Also, similar to the inclination angle of $-30^{\circ}$, the bubbly flow region is even more shrunk in the inclination

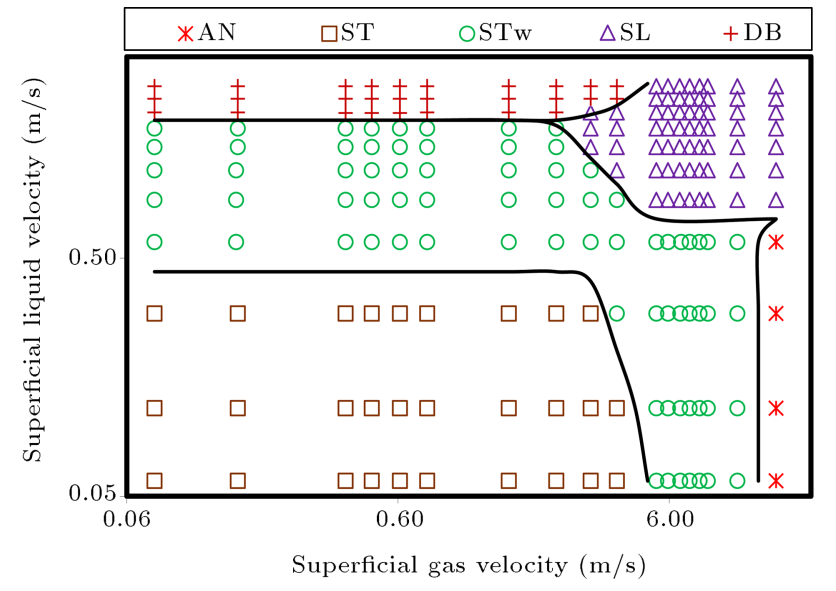

Figure 15. Experimental flow pattern map of air-light oil downward two-phase flow in pipe with the inclination angle of $-45^{\circ}$.

angle of $-45^{\circ}$. Also, annular flow is obtained only at high superficial velocities of air. Moreover, most parts of the flow pattern map are occupied with the stratified flow in this inclination angle. This occupation in flow pattern map is due to buoyancy force that acts as a resistant force in downward flow and is enhanced in high inclined downward flows. In highly inclined flows such as flows in pipes with inclination angles of $-30^{\circ}$ and $-45^{\circ}$, most of the examined points have been replaced by wavy stratified flow, and the number of bubbly and slug flows has decreased in the flow map.

Buoyancy force decelerates the dispersed phase and gravity force similarly accelerates it for inclined downward flow. It is concluded that stratified flows become the dominant flow regime and transition boundaries shift to the upper- and right-hand sides of the flow regime map.

The major parameters that create effective forces on each phase are the velocity as well as density and viscosity differences between air and oil. Buoyancy and gravity forces are strong functions of these factors, and it is concluded that various flow patterns are created based on these parameters. These effective forces are influenced by the pipe inclination angle; therefore, it is concluded that flow regimes are functions of pipe inclination angle as well. Finally, it should be mentioned that pipe diameter is another effective parameter in flow regimes.

\subsection{Inclined flows summary}

To sum up, effects of pipe inclination angle (upward, downward, and horizontal flows) on flow pattern maps of air-light oil two-phase flow are presented in the following. Flow pattern maps in inclination angles of $0^{\circ}$ and $+30^{\circ}$ are depicted in Figure 16. It is obvious that the increase in the pipe inclination angle from $0^{\circ}$ to $+30^{\circ}$ moves the transition boundaries between slug and bubbly flows and between plug and slug flows to 


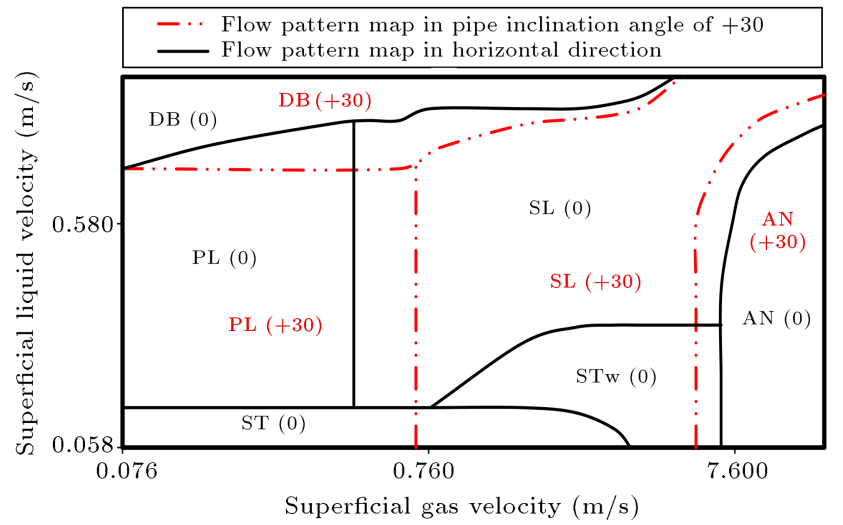

Figure 16. Comparison of horizontal and inclined upward $\left(+30^{\circ}\right)$ flow pattern maps in air-light oil two-phase flow.

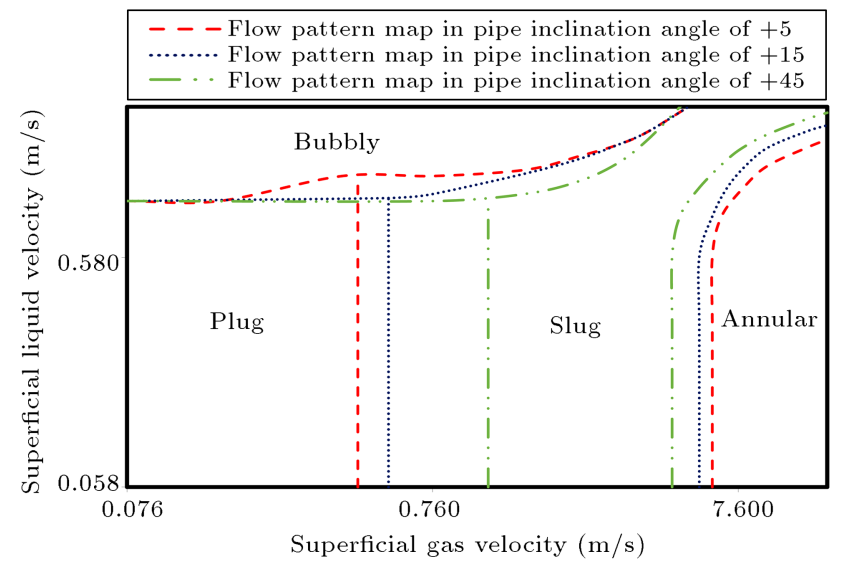

Figure 17. Effects of inclination angle on transition boundary in flow regime maps of upward two-phase flow.

the right-hand side of the flow regime map. Also, the transition boundary between annular and slug flows is shifted to the left.

To find out the effects of inclination angle on transition boundary in flow regime maps of upward two-phase flow, Figure 17 compares the flow regime maps in the pipe inclination angles of $+5^{\circ},+15^{\circ}$, and $+45^{\circ}$. It is clear that by increasing the inclination angle up to $+45^{\circ}$, the transition boundary between plug and slug flows shifts further to the right-hand side of the flow map and the transition boundary between annular and slug flow shifts to the lower air superficial velocity.

Flow pattern maps in inclination angles of $0^{\circ}$ and $-30^{\circ}$ are presented in Figure 18. The figure reveals that the decrease in the pipe inclination angle from $0^{\circ}$ to $-30^{\circ}$ moves the transition boundary between stratified and non-stratified flows to the upper parts of the flow regime map, and most areas of the flow map have been occupied by the stratified flows. Also, the transition boundary between annular and slug flows is shifted to the right-hand side of the flow regime map by decreasing the pipe inclination angle.

To find out the effects of inclination angle on the

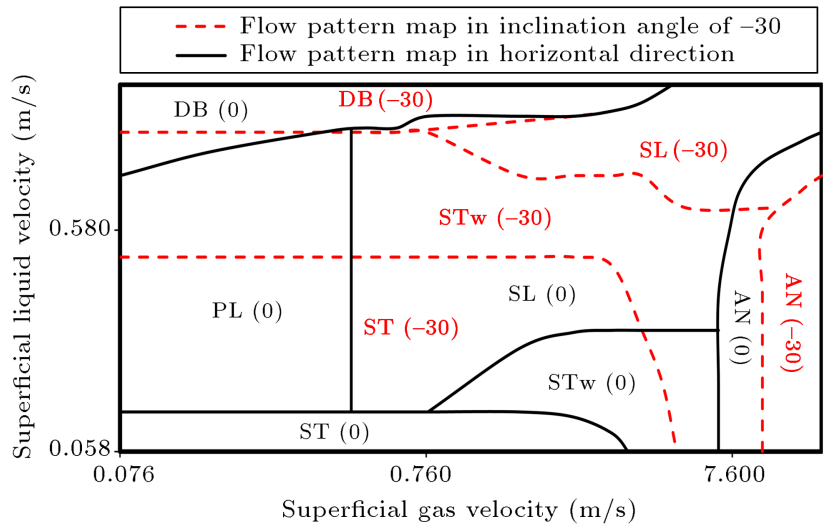

Figure 18. Comparison of horizontal and inclined downward $\left(-30^{\circ}\right)$ flow pattern maps in air-light oil two-phase flow.

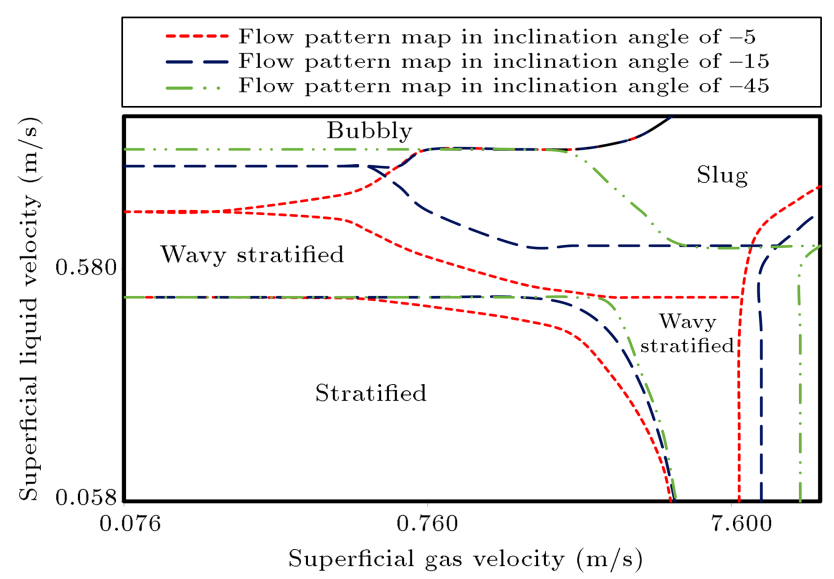

Figure 19. Effects of inclination angle on transition boundary in flow regime maps of downward two-phase flow.

transition boundary in flow regime maps of downward two-phase flow, Figure 19 compares the flow regime maps in the pipe inclination angles of $-5^{\circ},-15^{\circ}$, and $-45^{\circ}$. It is found that by decreasing the inclination angle up to $-45^{\circ}$, the transition boundary between bubbly and slug flows shifts further to the right-hand side of the flow map, and the transition boundary between annular and wavy stratified flows shifts to the higher air superficial velocity. In addition, flow regime transition from wavy stratified flow to bubbly flow occurs in higher oil superficial velocity. Considering the provided details above, in highly downward flows, stratified flow occupies most parts of the flow pattern map.

\section{Conclusion}

Air-light oil two-phase flow patterns in an inclined pipe were investigated experimentally. Flow patterns were determined for both upward and downward flows in inclination angles from $-45^{\circ}$ to $+45^{\circ}$. For each 
inclination angle, a flow regime map was extracted from the raw experimental data, and the obtained maps were compared to detect the effects of the inclination angle on transition boundaries between different flow regimes. In addition, the dominant flows were identified for both upward and downward flows. For the wide range of experimental conditions performed in this study, the following can be concluded:

- Dispersed phase in two-phase gas-liquid flow is affected by three forces: buoyancy, gravity, and inertia forces (there are some other forces due to phases' velocity and viscosity differences ignored in this study due to the least effects in comparison with other forces). In upward flows, gravity decelerates flow and buoyancy accelerates it. In contrast with upward flows, gravity accelerates flow and buoyancy decelerates it in downward flows;

- With the increase in the pipe inclination angle in air-light oil two-phase upward flow, the transition boundaries between slug and bubbly flows and slug and plug flows drifted to the right-hand side of the flow regime map, and transition boundary between annular and slug flows is shifted to the left, such that in high inclination angles, slug flow had the least occupied area in comparison with lower inclination angles. In addition, in highly upward flows, bubbly and plug flows approximately occupied more than half of the flow pattern map;

- By decreasing the pipe inclination angle in airlight oil two-phase downward flow, the transition boundaries between bubbly and slug flows and between slug and annular flows are shifted to the right-hand side of the flow pattern map. In highly inclination angles of downward flow, most of the annular flows were replaced by the churn and wavy stratified flows; it is predictable that by decreasing the inclination angle, the annular flow will disappear. Also, with decreasing the pipe inclination angle, stratified flow became dominant flow pattern, such that in inclination angle of $-45^{\circ}$, stratified and wavy stratified flows approximately occupied more than three quarters of the map;

- In upward flows, transition boundaries of the flow map were drifted only in the horizontal direction, while transition boundaries were shifted in both vertical and horizontal directions of the flow regime map in downward flows.

\section{Acknowledgement}

The financial support for this work was provided by the Iranian National Science Foundation (INSF) under Grant Number of 93036137.

\section{References}

1. Mandhane, J.M., Gregory, G.A. and Aziz, K. "A flow pattern map for gas-liquid flow in horizontal pipe", Int. J. Multiphase Flow, 1, pp. 537-553 (1974).

2. Weisman, J., Duncan, D., Gibson, J. and Crawford, T. "Effect of fluid properties and pipe diameter on two-phase flow patterns in horizontal lines", Int. J. Multiphase Flow, 5, pp. 437-462 (1979).

3. Lin, P.Y. and Hanratty, T.J. "Effect of pipe diameter on flow pattern for air-water flow in horizontal pipes", Int. J. Multiphase Flow, 13(4), pp. 549-563 (1987).

4. Jepson, W.P. and Taylor, R.E. "Slug flow and its transitions in large-diameter horizontal pipes", Int. J. Multiphase Flow, 19(3), pp. 411-420 (1993).

5. Lu, G., Wang, J. and Jia, Z. "Experimental and numerical investigations on horizontal oil-gas flow", $J$. Hydrodynam. B, 19(6), pp. 683-689 (2007).

6. Jamari, S., Hale, C.P., Hewitt, G.F. and Richardson, S.M. "Studies of the slug-annular regime transition in two-phase flow in horizontal pipes", Multiphase Sci. Tech., 20(1), pp. 1-24 (2008).

7. Foletti, C., Farise, S., Grassi, B., Strazza, D., Lancini, M. and Poesio, P. "Experimental investigation on twophase air/high-viscosity-oil flow in a horizontal pipe", Chem. Eng. Sci., 66, pp. 5968-5975 (2011).

8. Baker, D. "Simultaneous flow of oil and gas", Oil Gas $J .$, 53, pp. 183-195 (1954).

9. Petalas, N. and Aziz, K. "A mechanistic model for multiphase flow in pipes", J. Can. Pet. Tech., 39, pp. 43-55 (1998).

10. Matsubara, H. and Naito, K. "Effect of liquid viscosity on flow pattern of gas-liquid two phase flow in a horizontal pipe", Int. J. Multiphase Flow, 37, pp. 12771281 (2011).

11. Zhao, Y., Yeung, H., Zorgani, E.E., Archibong, A.E. and Lao, L. "High viscosity effects on characteristics of oil and gas two-phase flow in horizontal pipes", Chem. Eng. Sci., 95, pp. 343-352 (2013).

12. Monni, G., De Salve, M. and Panell, B. "Horizontal two-phase flow pattern recognition", Exp. Therm. Fluid Sci., 59, pp. 213-221 (2014).

13. Khaledi, H.A., Smith, I.E., Unander, T.E. and Nossen, J. "Investigation of two-phase flow pattern, liquid holdup and pressure drop in viscous oil-gas flow", Int. J. Multiphase Flow, 67, pp. 37-51 (2014).

14. Barnea, D., Shoham, O. and Taitel, Y. "Flow pattern transition for gas-liquid flow in horizontal and inclined pipes", Int. J. Multiphase Flow, 6, pp. 217-225 (1980).

15. Taitel, Y. and Duckler, A.E. "A model for predicting flow regime transitions in horizontal and near horizontal gas-liquid flow", AICHE J., 22, pp. 47-55 (1976).

16. Barnea, D., Shoham, O. and Taitel, Y. "Flow pattern for downward inclined two phase flow; horizontal to vertical", Chem. Eng. Sci., 37(5), pp. 735-740 (1982). 
17. Kokal, S.L. and Stanislav, J.F. "An experimental study of two-phase flow in slightly inclined pipes-I. Flow patterns", Chem. Eng. Sci., 44(3), pp. 665-679 (1989).

18. Wongwises, S. and Pipathattakul, M. "Flow pattern, pressure drop and void fraction of two-phase gas liquid flow in an inclined narrow annular channel", Exp. Therm. Fluid Sci., 30, pp. 345-354 (2006).

19. Ghajar, A.J. and Bhagwat, S.M. "Gas-liquid twophase flow phenomenon in near horizontal upward and downward inclined pipe orientations", Int. J. Mech. Aero. Ind. Mech. Manuf. Eng., 8(6), pp. 1091-1105 (2014).

20. Hanafizadeh, P., Eshraghi, J., Taklifi, A. and Ghanbarzadeh, S. "Experimental identification of flow regimes in gas-liquid two phase flow in a vertical pipe", Meccanica, 51(8), pp. 1771-1782 (2016).

21. Hanafizadeh, P., Hojati, A. and Karimi, A. "Experimental investigation of oil-water two phase flow regime in an inclined pipe", J. Pet. Sci. Eng., 136, pp. 12-22 (2015).

22. Ghanbarzadeh, S., Hanafizadeh, P. and Saidi, M.H. "Intelligent image-based gas-liquid two-phase flow regime recognition", ASME Fluid Eng. J., 134(6), pp. 061302-1-061302-10 (2012).

23. Ghajar, A.J. and Tang, C.C. "Heat transfer measurements, flow pattern maps, and flow visualization for non-boiling two-phase flow in horizontal and slightly inclined pipe", J. Heat Transf. Eng., 28, pp. 525-540 (2007).

24. Xia, G. and Chai, L. "Influence of surfactant on two phase flow regime and pressure drop in upward inclined pipes", J. Hydrodynam., 24(1), pp. 39-49 (2012).

25. Smith, I.E., Krampa, F., Fossen, M., Brekken, C., Kjølaas, J. and Unander, T.E. "Investigation of horizontal two-phase gas-liquid pipe flow using high viscosity oil: Comparison with experiments using low viscosity oil and flow simulations", 15th Int. Conf. on Multiphase Prod. Tech., Cannes, France, pp. 293-307 (2011).

26. Hanafizadeh, P., Karimi, A., Tklifi, A. and Hojati, A. "Experimental investigation of two-phase wateroil flow pressure drop in inclined pipes", Exp. Therm. Fluid Sci., 74, pp. 169-180 (2016).

27. Xi-mao, L., Hai-quan, Z., Ying-chuan, L., Zhongneng, L. and Qi, W. "Experimental study of flow patterns and pressure drops of heavy oil-water-gas vertical flow", J. Hydrodyn. Ser. B, 26, pp. 646-653 (2014).

28. Zhao, Y., Lao, L. and Yeung, H. "Investigation and prediction of slug flow characteristics in highly viscous liquid and gas flows in horizontal pipes", Chem. Eng. Res. Des., 102, pp. 124-137 (2015).

29. Losi, G., Arnone, D., Correra, S. and Poesio, P. "Modelling and statistical analysis of high viscosity oil/air slug flow characteristics in a small diameter horizontal pipe", Chem. Eng. Sci., 148, pp. 190-202 (2016).
30. Losi, G. and Poesio, P. "An experimental investigation on the effect of viscosity on bubbles moving in horizontal and slightly inclined pipes", Exp. Therm. Fluid Sci., 75, pp. 77-88 (2016)

31. Al-Safran, E., Kora, C. and Sarica, C. "Prediction of slug liquid holdup in high viscosity liquid and gas twophase flow in horizontal pipes", J. Petrol. Sci. Eng., 133, pp. 566-575 (2015).

\section{Biographies}

Pedram Hanafizadeh is an Associate Professor in the School of Mechanical Engineering, College of Engineering, University of Tehran, Iran. He received his $\mathrm{PhD}$ in Mechanical Engineering from Sharif University of Technology in 2010. He has co-authored more than 85 journal and conference publications. His research interests include experimental and numerical analyses of multi-phase flow, heat transfer in boiling and condensation, instrumentation in fluid flow, image processing for flow field analysis, design of heat exchangers and industrial application of multi-phase flow.

Javad Eshraghi was born in 1990. He graduated from Allame Helli high school (NODET-National Organization for Developing Exceptional Talents) and was awarded Full scholarship to the University of Tehran for Undergraduate and Graduate Programs in September 2009 and September 2013, respectively. He graduated from the Mechanical Engineering Department of the University of Tehran. During his graduate studies, he was a top member of Multi-Phase Flow Laboratory in Mechanical Engineering Department and published many research papers in this area.

Yasin Nazari received his MSc in Mechanical Engineering from University of Tehran, Alborz Campus. His research interests include multiphase flow and energy conversion.

Kaveh Yousefpour received his BSc in Mechanical Engineering from Islamic Azad University-South Tehran Branch, in 2012. He also received his MSc in Mechanical Engineering from University of Tehran, Alborz Campus, in 2015, in the field of energy conversion.

Mohammad Ali Akhavan-Behabadi is a Professor in the School of Mechanical Engineering, College of Engineering, University of Tehran, Iran. He received his $\mathrm{PhD}$ from Indian Institute of Technology at Roorkee in 1993. He has co-authored more than 150 journal and conference publications. His research interests include experimental convective heat transfer. $\mathrm{He}$ is currently working on augmentation of heat transfer by different techniques and also nano-fluids in single and two phase flow. 